\title{
BioTechnology: An Indian Journal
}

\section{Invitation to Contribute Manuscript to the 2021-Regular Issue of "BioTechnology:}

\section{An Indian Journal"}

\author{
Gloria Simmons* \\ Editorial Office, UK \\ *Corresponding author: Gloria Simmons, Editorial Office, UK, E-Mail: gloriasim@ gmail.com
}

Received: March 02, 2021; Accepted: March 16, 2021; Published: March 23, 2021

\begin{abstract}
Announcement
I'm delighted to introduce you to BioTechnology: An Indian Journal, a reputable Trade Science Publishers publication. The journal has successfully published 16 volumes, totaling approximately 500 high-quality articles. The journal covers a wide range of biotechnology topics. Our main goal is to disseminate high-quality, authentic research for the benefit of society. Humans gained wisdom at the cost of new complications, death, and impediment. Though such pebbles were never successful in stifling humanity's progress.
\end{abstract}

Rather than making them more inexperienced and inefficient, those inconveniences made them more experienced and effective. Researchers are aided in their quest for novel inventions and significant discoveries by peer review of findings and proper documentation through a digital platform. Our editorial board and expert reviewers have proved to be a valuable asset in the publishing of high-quality papers. I'd like to ask you to contribute related articles within the scope of the journal in order to collect some timely research works in the current Volume 17. All manuscripts submitted to the Journal are subjected to a rigorous double-blind peer review process. All types of manuscripts on all aspects of biotechnology are welcome.

You may submit the manuscript online via https://www.scholarscentral.org/submissions/biotechnology-an-indian-journal.html OR as an email attachment to biotechnology@ tradescience.org 